\title{
Erratum to: Assessment of chemical variability of major bottled waters in Sri Lanka
}

\author{
D. T. Udagedara $\cdot$ D. T. Jayawardana $\cdot$ \\ S. K. Pelpitiya
}

Published online: 13 January 2015

(C) Springer-Verlag Berlin Heidelberg 2015

\section{Erratum to: Environ Earth Sci}

\section{DOI 10.1007/s12665-014-3955-5}

The authors would like to correct the errors in the original publication as detailed below.

The correct version of the author list is given here:

D. T. Udagedara - D. T. Jayawardana $\cdot$ S. K. Pelpitiya

The online version of the original article can be found under doi:10.1007/s12665-014-3955-5.

D. T. Udagedara $\cdot$ S. K. Pelpitiya

Uva Wellassa University, Badulla 90000, Sri Lanka

e-mail: tharangau@yahoo.com

S. K. Pelpitiya

e-mail: sandamrt@gmail.com

D. T. Udagedara

Department of Civil and Environmental Engineering, Geosphere

Research Institute, Saitama University, Saitama 338-8570, Japan

D. T. Jayawardana $(\bowtie)$

Department of Forestry and Environmental Science, Faculty of Applied Science, Sri Jayewardenepura University, Gangodawila, Nugegoda, Sri Lanka

e-mail: daham@sci.sjp.ac.lk 